Article

\title{
The Impact of Cryptolaemus montrouzieri Mulsant (Coleoptera: Coccinellidae) on Control of Dysmicoccus neobrevipes Beardsley (Hemiptera: Pseudococcidae)
}

\author{
Zhenqiang Qin ${ }^{1, *}$, Jianhui Wu ${ }^{2}$, Baoli Qiu ${ }^{2}$, Shaukat Ali ${ }^{2}$ and Andrew G. S. Cuthbertson ${ }^{3}$ \\ 1 Sugarcane Research Institute, Guangxi Academy of Agricultural Sciences, Nanning 530007, China \\ 2 Department of Entomology, South China Agricultural University/Engineering Research \\ Centre of Biological Control, Ministry of Education, Guangzhou 510640, China; jhw@scau.edu.cn (J.W.); \\ baileyqiu@scau.edu.cn (B.Q.); aliscau@scau.edu.cn (S.A.) \\ 3 Independent Science Advisor, York YO10 5AQ, UK; andrew_cuthbertson@live.co.uk \\ * Correspondence: qinzqcn@163.com; Tel.: +86-182-7573-2089
}

Received: 14 February 2019; Accepted: 1 May 2019; Published: 6 May 2019

check for updates

\begin{abstract}
Cryptolaemus montrouzieri (Coleoptera: Coccinellidae) is an important predator of the mealybug Dysmicoccus neobrevipes (Hemiptera: Pseudococcidae), a major pest of Agave sisalana in $C$ ina. Limited reports on the efficacy of $C$. montrouzieri against $D$. neobrevipes are available. This study reports the predatory efficacy and functional response of $C$. montrouzieri against $D$. neobrevipes under laboratory conditions. The prey consumption rate per day of 4 th instar larvae of $C$. montrouzieri feeding on 1st instar D. neobrevipes nymphs (241.3 mealybugs) was the highest among the different larval life stages of the beetle. For C. montrouzieri, the prey consumption per day of adult females (19.8 mealybugs) was significantly higher compared to males (15.2 mealybugs) when feeding on 3rd instar D. neobrevipes nymphs. The functional responses of $C$. montrouzieri on 1 st and 2 nd instar $D$. neobrevipes nymphs were determined as Holling type II. The search rates of $C$. montrouzieri 4 th instar larvae towards the 1st and 2nd instar nymphs of $D$. neobrevipes were higher than those of the other beetle life stages. In addition, the handling times of 4th instar larvae were shorter than those of the other beetle life stages. The results from this study indicate that $C$. montrouzieri can be used as a predator of $D$. neobrevipes and, therefore, it should be evaluated further for use as a biocontrol agent in D. neobrevipes management programs.
\end{abstract}

Keywords: Cryptolaemus montrouzieri; Dysmicoccus neobrevipes; efficacy; biological control

\section{Introduction}

The coccinellid Cryptolaemus montrouzieri Mulsant (Coleoptera: Coccinellidae) has been used all over the world as a biological control agent against mealybugs [1]. C. montrouzieri, also known as the mealybug destroyer, is a very efficient natural enemy of mealybug pests since its larvae and adult life stages both feed on the prey. It has also been successfully mass-reared within insectaries and transferred to citrus orchards and grape vineyards, as well as into glasshouses where mealybugs were a major problem [2]. In China, C. montrouzieri was introduced during 1955 from what was then the Soviet Union. It has been subsequently released to aid in the control of local populations of mealybugs, e.g., against Pseudococcus sp., a pest of Aleurites moluccana around the cities of Guangzhou and Foshan in Guangdong Province, China [3].

The grey pineapple mealybug, Dysmicoccus neobrevipes Beardsley (Hemiptera: Pseudococcidae), is an important pest of many economically important plants, such as Agave spp., Cucurbita pepo L., 
and C. maxima Duchesne [4]. Feeding by D. neobrevipes may cause leaf yellowing, defoliation, reduced plant growth and, in some cases, plant death. This mealybug is also a primary vector of the pineapple mealybug wilt-associated virus (PMWaV) [4]. In China, D. neobrevipes was first recorded in the Changjiang County, Hainan Province, where it was damaging A. sisalana in 1998, a major economic crop in South China [5]. Since 2006, D. neobrevipes has been observed on A. sisalana in Zhanjiang City, Guangdong Province, and its distribution has increased from 2670 ha to 6700 ha [6]. In addition, D. neobrevipes has recently also been observed on A. sisalana in the Pubei County, Guangxi Province, and on A. sisalana, A. americana var. marginata, and other crops in Jinghong City, Yunnan Province [7].

An important characteristic of a predator, for evaluating its impact on a given prey population, is its functional response when describing the relationship between predation and prey density [8-10]. A proven and ecologically sound best management practice (BMP) for A. sisalana is that of using biological control agents that regulate pest populations to below an economic injury level. The effects of an artificial diet containing plant pollen, population admixture, mealybug sex pheromones, and heavy metals transferred across a multitrophic food chain on the development and behaviour of $C$. montrouzieri have recently been studied [11-14]. Moreover, the structures of the sex pheromones of D. neobrevipes were determined and synthesised, in order to develop an efficient lure for monitoring traps $[15,16]$. However, there are no reports available on the efficacy of $C$. montrouzieri against $D$. neobrevipes under laboratory conditions. Therefore, in this study, we aimed to determine the functional response of C. montrouzieri against $D$. neobrevipes. The results are expected to provide useful reference data on this predator's future use as a biocontrol agent for mealybug management.

\section{Materials and Methods}

\subsection{Insects}

D. neobrevipes was originally collected from A. sisalana plants at the farm of the Eastern Sisal Group Company in Zhanjiang City, Guangdong Province, China during December 2007. Individuals were maintained on ripe pumpkins under laboratory conditions $\left(26 \pm 1{ }^{\circ} \mathrm{C}, 75 \%-90 \%\right.$ Relative Humidity, 14:10 Light:Dark photoperiod) in the Department of Entomology, South China Agricultural University, Guangzhou, China. Before starting the experiments, D. neobrevipes individuals were reared on A. sisalana plants in order to synchronise the collection of nymphs and adults of the same age.

C. montrouzieri individuals were maintained by feeding them on Ferrisia virgata Cockerell (Hemiptera: Pseudococcidae) in cages $(60 \mathrm{~cm} \times 60 \mathrm{~cm} \times 60 \mathrm{~cm})$ under laboratory conditions as outlined above. Before starting the experiments, $C$. montrouzieri individuals were reared on $D$. neobrevipes from A. sisalana plants for at least five consecutive generations.

\subsection{Prey Consumption of D. neobrevipes by C. montrouzieri}

Gravid females of D. neobrevipes were placed on fresh A. sisalana leaves and were allowed to produce nymphs for 2-3 days. The number of newly hatched nymphs (200 mealybugs of $1^{\text {st }}$ instar for the lower instar predator larvae trials and 400 mealybugs for higher predator instar larvae and adult trials) was counted and then transferred into an empty Petri dish (diameter $9 \mathrm{~cm}$, height $1.5 \mathrm{~cm}$ ). A 1st instar C. montrouzieri larva was placed in the Petri dish which was then sealed with preservation membranes held in place using rubber bands. Consumption of $D$. neobrevipes by $C$. montrouzieri was observed after $24 \mathrm{~h}$ by using a Leica M10 stereomicroscope. The predator larva was then removed and placed into another Petri dish with the same number of $D$. neobrevipes nymphs for continued observation of prey consumption. A total of 10 predator larvae were observed over two days. The consumption rates of 2 nd to 4 th instar larvae of $C$. montrouzieri on D. neobrevipes $1^{\text {st }}$ instar nymphs were then observed as described above. In addition, the consumption of D. neobrevipes 2 nd and 3rd instar nymphs, immature female adults (within 3-5 days from the 3rd instar nymph to female), and mature female adults (after 20 days from the 3 rd instar nymph to female) by C. montrouzieri 3 rd and 4 th instar larvae were also determined as described above. 


\subsection{Functional Response of C. montrouzieri to D. neobrevipes}

Individual C. montrouzieri 1st instar larvae were starved for $24 \mathrm{~h}$ before experiments. First instar D. neobrevipes nymphs were counted and placed into a Petri dish along with one C. montrouzieri 1st instar larva. The dish was then sealed with preservation membranes held in place with rubber bands. Consumption of the 1 st instar $D$. neobrevipes nymphs by the $C$. montrouzieri 1st instar larvae was examined at five different prey densities $(25,50,100,200$, and 400 mealybugs) after $24 \mathrm{~h}$ (all replicated five times) under the conditions as described for the predator consumption experiments. In addition, consumption of the 1 st instar D. neobrevipes nymphs by C. montrouzieri individuals (2nd, 3rd, and 4th instar larvae, as well as female and male adults) at the five different prey densities was also determined as described above. Finally, the consumption of 2 nd instar D. neobrevipes nymphs by C. montrouzieri individuals (3rd and 4th instar larvae, as well as female and male adults) at the five different prey densities was also determined as earlier described.

\subsection{Statistical Analysis}

Consumption rates per individual per day were calculated and subjected to one-way ANOVA (IBM SPSS Statistics 20, Chicago, IL, USA). Where significant, means were separated by Duncan's method of multiple range test $(p<0.05)$.

The Holling type II functional response for C. montrouzieri predating on D. neobrevipes was fitted using the following formula [9]:

$$
N_{A}=\frac{T_{t} a N_{o}}{1+a b N_{o}}
$$

where $N_{A}$ is the number of mealybugs eaten; $N_{o}$ is the density of mealybugs; $T_{t}$ is the total time for predators to find and deal with prey ( 1 day $(24 \mathrm{~h}))$; $a$ is the searching rate; and $b$ is the handling time. The searching rate (the ratio of a predator's successful captures to contacts with prey) and handling time (including identification, capture, and consumption of prey) of C. montrouzieri predating on $D$. neobrevipes were fitted under the different prey densities [9]. Here, $T_{t}$ in this experiment is 1 , therefore, the formula can then be changed to the following:

$$
N_{A}=a N_{o} /\left(1+a b N_{o}\right)
$$

The mean consumption of $D$. neobrevipes by C. montrouzieri at different prey densities (all replicated five times) was calculated. The mean consumption by $C$. montrouzieri of $D$. neobrevipes $\left(N_{A}\right)$ and the densities $\left(N_{o}\right)$ were fitted, and the searching rate $(a)$ and handling time $(b)$ were estimated (SAS 8.1 Institute, 2000, Cary, NC, USA). In addition, the correlation coefficient was analysed between the theoretical value and the experimental result with regard to the consumption of $D$. neobrevipes by C. montrouzieri.

\section{Results}

\subsection{Prey Consumption of D. neobrevipes by C. montrouzieri}

There were significant differences among the prey consumption rates per day of $C$. montrouzieri larvae on the 1st instar nymphs of $D$. neobrevipes, as seen in Table 1 . The prey consumption per day of 4th instar larvae (241.3 mealybugs/day, $\mathrm{SE}=19.38 ; F=75.615 ; \mathrm{df}=3,36 ; p<0.001)$ of $C$. montrouzieri feeding on the 1st instar nymphs of $D$. neobrevipes was highest among the different larval life stages of the beetle. There were significant differences between the prey consumption per day of 3rd instar larvae and 4th instar larvae of $C$. montrouzieri feeding on the 3rd instar nymph (for 3rd instar larvae 12.2 mealybugs/day, $\mathrm{SE}=0.88$; for 4 th instar larvae 23.4 mealybugs/day, $\mathrm{SE}=1.83 ; F=30.028 ; \mathrm{df}=1,18$; $p<0.001$ ) and mature adults (for 3rd instar larvae 0.7 mealybugs/day, $\mathrm{SE}=0.20$; for 4 th instar larvae 1.6 mealybugs/day, $\mathrm{SE}=0.35 ; F=5.631 ; \mathrm{df}=1,18 ; p=0.029)$ of $D$. neobrevipes. The prey consumption per day of 3rd and 4th instar larvae of C. montrouzieri feeding on the 2nd instar nymph (for 3rd instar larvae 
41.6 mealybugs/day, $\mathrm{SE}=2.49$; for 4th instar larvae 50.1 mealybugs/day, $\mathrm{SE}=3.82 ; F=3.515 ; \mathrm{df}=1,18$; $p=0.077$ ) and immature adults (for 3rd instar larvae 6.2 mealybugs/day, $\mathrm{SE}=0.27$; for 4th instar larvae 9.3 mealybugs/day, $\mathrm{SE}=1.68 ; F=3.305 ; \mathrm{df}=1,18 ; p=0.086$ ) of $D$. neobrevipes were similar to each other. There were significant differences among the prey consumption rates per day of $C$. montrouzieri 3 rd and 4th instar larvae on the 1st and 2nd instar nymphs of $D$. neobrevipes compared to the other life stages tested in this study, and no significant differences on 3rd instar nymphs, immature or mature mealybug adults. In addition, there was a significant difference between the prey consumption rates per day of female and male adults of $C$. montrouzieri feeding on the 3rd instar nymphs (for female adults 19.8 mealybugs/day, $\mathrm{SE}=1.21$; for males 15.2 mealybugs/day, $\mathrm{SE}=1.46 ; F=5.877 ; \mathrm{df}=1,18$; $p=0.026)$ of $D$. neobrevipes. The results from the study showed that there were significant differences among the prey consumption rates per day of $C$. montrouzieri female adults on the 1 st and 2 nd instar nymphs of $D$. neobrevipes compared with the other life stages tested, and no significant differences between 3rd instar nymphs with immature adults and mature adults. In turn, for C. montrouzieri male adults, there were significant differences among the prey consumption rates per day of the predator on the 1st and 2nd instar nymphs of D. neobrevipes compared with the other life stages tested, and no significant differences on 3rd instar nymphs, immature and mature mealybug adults, as seen in Table 2.

Table 1. Prey consumption rates per day (mean \pm standard error) for different larval stages of Cryptolaemus montrouzieri on different life stages of Dysmicoccus neobrevipes.

\begin{tabular}{|c|c|c|c|c|c|c|c|c|}
\hline \multirow{2}{*}{ C. montrouzieri } & \multirow{2}{*}{$\begin{array}{l}\text { 1st instar } \\
\text { nymph }\end{array}$} & \multirow{2}{*}{$\begin{array}{l}\text { 2nd instar } \\
\text { nymph }\end{array}$} & \multirow{2}{*}{$\begin{array}{l}\text { 3rd instar } \\
\text { nymph }\end{array}$} & \multicolumn{5}{|c|}{ D. neobrevipes } \\
\hline & & & & Immature Adult & Mature Adult & $F$ & df & $\operatorname{Pr}>F$ \\
\hline 1st instar larvae & $20.1 \pm 2.92 \mathrm{~d}$ & - & - & - & - & & & \\
\hline 2nd instar larvae & $66.1 \pm 5.35 c$ & - & - & - & - & & & \\
\hline 3rd instar larvae & $108.9 \pm 8.21 \mathrm{~b} \mathrm{~A}$ & $41.6 \pm 2.49$ a B & $12.2 \pm 0.88 \mathrm{~b} \mathrm{C}$ & $6.2 \pm 0.27$ a C & $0.7 \pm 0.20 \mathrm{~b} \mathrm{C}$ & 134.689 & 4,45 & 0.000 \\
\hline 4th instar larvae & $241.3 \pm 19.38$ a A & $50.1 \pm 3.82$ a B & $23.4 \pm 1.83 \mathrm{a} \mathrm{C}$ & $9.3 \pm 1.68$ a C & $1.6 \pm 0.35$ a C & 126.532 & 4,45 & 0.000 \\
\hline$F$ & 75.615 & 3.515 & 30.028 & 3.305 & 5.631 & & & \\
\hline $\mathrm{df}$ & 3,36 & 1,18 & 1,18 & 1,18 & 1,18 & & & \\
\hline $\operatorname{Pr}>F$ & 0.000 & 0.077 & 0.000 & 0.086 & 0.029 & & & \\
\hline
\end{tabular}

Means in columns followed by different small letters are significantly different among the prey consumption rates per day for different larval stages of $C$. montrouzieri on the same life stages of $D$. neobrevipes $(p<0.05)$ according to Duncan's multiple range test, and different capital letters are significantly different among the prey consumption rates per day for 3rd and 4 th larvae of $C$. montrouzieri on different life stages tested of D. neobrevipes $(p<0.05)$ according to Duncan's multiple range test.

Table 2. Prey consumption rates (mean \pm standard error) per day for adult Cryptolaemus montrouzieri on different life stages of Dysmicoccus neobrevipes.

\begin{tabular}{|c|c|c|c|c|c|c|c|c|}
\hline \multirow{2}{*}{ C. montrouzieri } & \multirow{2}{*}{$\begin{array}{l}\text { 1st instar } \\
\text { nymph }\end{array}$} & \multirow{2}{*}{$\begin{array}{l}\text { 2nd instar } \\
\text { nymph }\end{array}$} & \multirow{2}{*}{$\begin{array}{l}\text { 3rd instar } \\
\text { nymph }\end{array}$} & \multicolumn{5}{|c|}{ D. neobrevipes } \\
\hline & & & & Immature Adult & Mature Adult & $F$ & df & $\operatorname{Pr}>F$ \\
\hline Female adult & $95.8 \pm 6.89$ a A & $56.2 \pm 5.48$ a B & $19.8 \pm 1.21 \mathrm{a} \mathrm{C}$ & $11.8 \pm 0.73 \mathrm{a} C D$ & $1.1 \pm 0.05$ a D & 95.015 & 4,45 & 0.000 \\
\hline Male adult & $86.9 \pm 11.21$ a A & $47.6 \pm 6.82$ a B & $15.2 \pm 1.46 \mathrm{bC}$ & $10.4 \pm 1.02 \mathrm{a} \mathrm{C}$ & $1.3 \pm 0.13$ a C & 35.290 & 4,45 & 0.000 \\
\hline F & 0.458 & 0.966 & 5.877 & 1.368 & 1.433 & & & \\
\hline df & 1,18 & 1,18 & 1,18 & 1,18 & 1,18 & & & \\
\hline $\operatorname{Pr}>F$ & 0.507 & 0.339 & 0.026 & 0.257 & 0.247 & & & \\
\hline
\end{tabular}

Means in columns followed by different small letters are significantly different among the prey consumption rates per day for female and male adults of $C$. montrouzieri on the same life stages of $D$. neobrevipes $(p<0.05)$ according to Duncan's multiple range test, and different capital letters are significantly different among the prey consumption rates per day for female and male adults of $C$. montrouzieri on different life stages tested of $D$. neobrevipes $(p<0.05)$ according to Duncan's multiple range test.

\subsection{Functional Response of C. montrouzieri to D. neobrevipes}

The functional responses of $C$. montrouzieri predating on $D$. neobrevipes were determined as Holling type II. The search rate of C. montrouzieri 4th instar larvae (1.0716) feeding on the 1st instar nymphs of D. neobrevipes was higher than those of the predator on other life stages, whereas the handling time of 4 th instar larvae (0.00123) was shorter than that of the predator for other life stages. When preying on D. neobrevipes 2 nd instar nymphs, the search rate of C. montrouzieri 4 th instar larvae (1.0124) was also higher than that of other life stages and, in addition, the handling time of 4 th instar larvae (0.0108) was shorter than that of other life stages of the predator, as seen in Table 3. 
Table 3. Functional response parameters and Holling type II model of Cryptolaemus montrouzieri life stages to 1st and 2nd instar nymphs of Dysmicoccus neobrevipes.

\begin{tabular}{cccccc}
\hline C. montrouzieri & D. neobrevipes & Search Rate & $\begin{array}{c}\text { Handling } \\
\text { Times }\end{array}$ & $\begin{array}{c}\text { Correlation } \\
\text { Coefficient }\end{array}$ & Holling Type II Model \\
\hline 1st instar larvae & & 0.8217 & 0.0117 & 0.9944 & $N_{A}=0.8217 N_{o} /\left(1+0.00961389 N_{o}\right)$ \\
2nd instar larvae & & 0.8899 & 0.00859 & 0.9878 & $N_{A}=0.8899 N_{o} /\left(1+0.007644241 N_{o}\right)$ \\
3rd instar larvae & 1st instar nymphs & 0.9314 & 0.00347 & 0.9962 & $N_{A}=0.9314 N_{o} /\left(1+0.003231958 N_{o}\right)$ \\
4th instar larvae & & 1.0716 & 0.00123 & 0.9994 & $N_{A}=1.0716 N_{o} /\left(1+0.001318 N_{o}\right)$ \\
Female adult & & 0.9257 & 0.00648 & 0.9814 & $N_{A}=0.9257 N_{o} /\left(1+0.005998536 N_{o}\right)$ \\
Male adult & & 0.9193 & 0.00772 & 0.9966 & $N_{A}=0.9193 N_{o} /\left(1+0.007096996 N_{o}\right)$ \\
\hline 3rd instar larvae & & 0.9349 & 0.0122 & 0.9991 & $N_{A}=0.9349 N_{o} /\left(1+0.01140578 N_{o}\right)$ \\
4th instar larvae & 2nd instar nymphs & 1.0124 & 0.0108 & 0.9834 & $N_{A}=1.0124 N_{o} /\left(1+0.010934 N_{o}\right)$ \\
Female adult & & 0.9373 & 0.0121 & 0.9816 & $N_{A}=0.9373 N_{o} /\left(1+0.01134133 N_{o}\right)$ \\
Male adult & & 0.9287 & 0.0127 & 0.9828 & $N_{A}=0.9287 N_{o} /\left(1+0.01179449 N_{o}\right)$ \\
\hline
\end{tabular}

Note: $N_{A}$ is the consumption by the predator C. montrouzieri of D. neobrevipes; $N_{o}$ is prey density.

\section{Discussion}

Adult mealybugs are difficult to control because of the thick waxy secretions they produce that surround their body. As a result, repeated application of chemicals targeting immatures have usually been applied to suppress their populations [17]. However, the current trend is to control the mealybugs by using biological controls. Natural predators are now the important biological agents being used for mealybug management in many countries. The reduction rate reached $100 \%$ for all life stages of Planococcus citri on Codiaeum variegatum after three months following the release of C. montrouzieri in Egypt [18]. The predatory coccinellid C. montrouzieri is considered as one of the most popular biological agents used for mealybug control [19-21]. Across the world, C. montrouzieri has been periodically introduced by means of augmentative releases against many species of mealybugs [2,22-25]. In China, C. montrouzieri is used as an effective natural enemy of mealybugs $[3,26,27]$. It has also been demonstrated that $C$. montrouzieri can complete its development (the development period of egg to adult is $29.3 \pm 1.19$ days) and reproduce $(38.9 \pm 4.43$ eggs) when feeding on D. neobrevipes, and its finite rate of increase is 0.0546 [28].

Many experiments have been conducted under laboratory conditions to measure the functional responses of predator coccinellids against psyllids, aphids, and mealybugs [25,29-31]. The results from the current study will now provide additional useful reference data for consumption of $D$. neobrevipes by C. montrouzieri under laboratory conditions. The prey consumption of 4 th instar larvae of $C$. montrouzieri on the 1st instar nymphs of $D$. neobrevipes were higher than all the other larval life stages of the predator. The functional responses of $C$. montrouzieri on the 1 st and 2 nd instar nymphs of $D$. neobrevipes were determined as Holling type II. Handling times decreased from the younger to older larvae of C. montrouzieri as expected, due to the higher consumption of prey, which is similar to the findings of Papanikolaou et al. [30]. The authors showed that all larval instars of Propylea quatuordecimpunctata (L.) exhibited a Holling type II functional response when searching for Aphis fabae Scopoli on Vicia faba plants [30]. Similarly, in the study by Qin et al. [27] it was shown that there was a significant difference between the average consumption per day of the 1st instar Saccharicoccus sacchari nymph by female and male adults of $C$. montrouzieri with 324.35 and 303.10 mealybugs consumed per day, respectively. The functional responses of the female and male adults of $C$. montrouzieri on $S$. sacchari nymphs were also determined as Holling type II [27].

In the Holling type II functional response, prey consumption increases asymptotically to a plateau with increasing prey density [30]. Functional response curves are used to understand the basic mechanisms that drive the interactions of predator-prey behaviour, to clarify co-evolutionary relationships and to improve practical predictive powers for biological control [32,33]. Although there are various types of functional responses described for coccinellids [34], type II is the most common [30]. That is, the number of discs removed from the table increase at a decreasing rate until the curves level off [9]. The effect of the density of A. fabae on each larval instar of P. quatuordecimpunctata showed that the coccinellid caused an inverse density-dependent mortality of its aphid prey [30]. Work by Silva et al. [29] showed that the prey host plants can affect the consumption rates of a predator at 
different densities under laboratory conditions, perhaps showing the need to involve the integration of biological control with host-plant resistance. A predator can also respond to the pheromone stimuli of its prey and can do this in a species-specific manner [14]. However, functional response experiments conducted under laboratory conditions may not be representative of field conditions [30]. The feeding potential is of great interest particularly with regard to predatory insects, where their ability in consuming prey is extremely vital for their success in biological control programs. Generally, in many biocontrol programs, augmentation of natural enemies is followed by either inoculative or inundative releases to achieve satisfactory control of target pests [35]. C. montrouzieri, as a natural predator used to control mealybugs [36], is considered safe to humans, a good alternative to conventional pesticides, amenable to small-scale local production and addresses increased public awareness of environmental concerns [20]. Therefore, the results of the present study provide a basic understanding of C. montrouzieri-prey interactions. However, C. montrouzieri should be further evaluated as a biological control agent in $D$. neobrevipes management programs in the field.

\section{Conclusions}

The results from this study indicate that $C$. montrouzieri can be used as a predator of D. neobrevipes and, therefore, it should be evaluated further for possible use as a biocontrol agent in $D$. neobrevipes management programs.

Author Contributions: Z.Q., J.W., and B.Q. conceived the research; Z.Q. conducted the experiments; Z.Q. and J.W. contributed experimental material; Z.Q. analysed the data and conducted all statistical analyses; Z.Q., J.W., B.Q., S.A., and A.G.S.C. contributed to the writing of the manuscript; all authors read and approved the manuscript.

Funding: This work was supported by the National Natural Science Foundation of China (31760540).

Acknowledgments: The authors thank Sanan Wu (Beijing Forestry University, Beijing, China) for the identification of Dysmicoccus neobrevipes.

Conflicts of Interest: The authors declare no conflicts of interest.

\section{References}

1. Gkounti, V.T.; Savopoulou-Soultani, M.; Milonas, P.G. Intra-and interspecific interactions between Nephus includes and Cryptolaemus montrouzieri. J. Appl. Entomol. 2015, 139, 647-653. [CrossRef]

2. Ozgokce, M.S.; Atlihan, R.; Karaca, I. The life table of Cryptolaemus montrouzieri Mulsant (Coleoptera: Coccinellidae) after different storage periods. J. Food Agric. Environ. 2006, 4, 282-287.

3. Li, L.Y. The research and application prospects of Cryptolaemus montrouzieri in China. Nat. Enemies Insects 1993, 15, 142-152.

4. Sether, D.M.; Ullman, D.E.; Hu, J.S. Transmission of pineapple mealybug wilt-associated virus by two species of mealybug (Dysmicoccus spp.). Phytopathology 1998, 88, 1224-1230. [CrossRef] [PubMed]

5. Wu, J.H.; Lin, L.; Ren, S.X.; Qin, Z.Q. New pest on sisal in Leizhou Peninsula-A briefing about gray pineapple mealybug, Dysmicoccus neobrevipes Beardsley. Guangdong Agric. Sci. 2008, 4, 47-48.

6. Qin, Z.Q.; Wu, J.H.; Qiu, B.L.; Ren, S.X.; Ali, S. Effects of host plant on development, survivorship and reproduction of Dysmicoccus neobrevipes Beardsley (Hemiptera: Pseudococcidae). Crop Prot. 2011, 30, 1124-1128. [CrossRef]

7. Qin, Z.Q.; Sugarcane Research Institute, Guangxi Academy of Agricultural Sciences, Nanning, China. Personal Observation, 2018.

8. Solomon, M.E. The natural control of animal population. J. Anim. Ecol. 1949, 18, 1-35. [CrossRef]

9. Holling, C.S. Principles of insect predation. Ann. Rev. Entomol. 1961, 6, 163-182. [CrossRef]

10. Murdoch, W.W.; Oaten, A. Predation and population stability. Adv. Ecol. Res. 1975, 9, 2-131.

11. Xie, J.Q.; Wu, H.S.; Pang, H.; Clercq, P.D. An artificial diet containing plant pollen for the mealybug predator Cryptolaemus montrouzieri. Pest Manag. Sci. 2017, 73, 541-545. [CrossRef]

12. Li, H.S.; Zou, S.J.; Clercq, P.D.; Pang, H. Population admixture can enhance establishment success of the introduced biological control agent Cryptolaemus montrouzieri. BMC Evol. Biol. 2018, 18, 36. [CrossRef]

13. Sang, W.; Xu, J.; Bashir, M.H.; Ali, S. Developmental responses of Cryptolaemus montrouziri to heavy metals transferred across multi-trophic food chain. Chemosphere 2018, 205, 690-697. [CrossRef] 
14. Urbina, A.; Verdugo, J.A.; Lopez, E.; Bergmann, J.; Zaviezo, T.; Flores, M.F. Searching behavior of Cryptolaemus montrouzieri (Coleoptera: Coccinellidae) in response to mealybug sex pheromones. J. Econ. Entomol. 2018, 111, 1996-1999. [CrossRef]

15. Tabata, J.; Ichiki, R.T. A New Lavandulol-related Monoterpene in the sex pheromone of the grey pineapple mealybug, Dysmicoccus neobrevipes. J. Chem. Ecol. 2015, 41, 194-201. [CrossRef]

16. Tabata, J.; Ohno, S. Enantioselective synthesis of the sex pheromone of the grey pineapple mealybug, Dysmicoccus neobrevipes (Hemiptera: Pseudococcidae), for determination of the absolute configuration. Appl. Entomol. Zool. 2015, 50, 341-346. [CrossRef]

17. Townsend, M.L.; Oetting, R.D.; Chong, J.H. Management of the mealybug Phenacoccus madeirensis. Proc. South Nursery Assoc. Res. Confer. 2000, 45, 162-166.

18. Afifi, A.I.; EI-Arnaouty, S.A.; Attia, A.R.; Alla, A.E.A. Biological control of Citrus Mealybug, Planococcus citri (Risso.) using Coccinellid predator, Cryptolaemus montrouzieri Muls. Pakistan J. Biol. Sci. 2010, 13, $216-222$. [CrossRef]

19. Hagen, K.S.; Mills, N.J.; Gordh, G.; McMurtry, J.A. Terrestrial Arthropod Predators of Insects and Mites Pests. In Handbook of Biological Control: Principles and Applications of Biological Control; Bellows, T.S., Fisher, T.W., Eds.; Academic Press: San Diego, CA, USA, 1999; pp. 383-504.

20. Basu, T. Adoption of biocontrol agents at the field level for management of mealybugs: Challenges and proposed solutions. J. Biopesticides 2010, 3, 55-57.

21. Maes, S.; Gregoire, J.C.; Clercq, P.D. Prey range of the predatory ladybird Crptolaemus montrouzieri. BioControl 2014, 59, 729-738. [CrossRef]

22. Mani, M. Studies on the natural enemies of oriental mealybug, Planococcus lilacinus (Ckll.) (Homoptera: Pseudococcidae) in India. J. Entomol. Res. 1995, 19, 61-70.

23. Mani, M.; Krishnamoorthy, A. Biological suppression of spherical mealybug Nipaecoccus viridis (Newstead) (Hemiptera, Pseudoccidae) on acid lime in India. Entomon. 2002, 27, 423-424.

24. Persad, A.; Khan, A. Comparison of life table parameters for Maconellicoccus hirsutus, Anagyrus kamali, Cryptolaemus montrouzieri and Scymnuscoccivora. BioControl 2002, 47, 137-149. [CrossRef]

25. Attia, A.R.; El-Arnaouty, S.A. Use of the coccinellid predator, Cryptolaemus montrouzieri Mulsant against the striped mealybug, Ferrisia virgata (Ckll.) on the ornamental plant, Agalypha macrophylla in Egypt. Egypt. J. Biol. Pest Control 2007, 17, 71-76.

26. Tang, C.; Pang, H.; Ren, S.X.; Pang, X.F. Studies on the Cryptolaemus montrouziri Mulsant feeding on loblolly pine mealybug Oracella acuta (Lobdell). Nat. Enemies Insects 1995, 17, 9-12.

27. Qin, Z.Q.; Wei, J.J.; Song, X.P.; Luo, Y.W.; Liu, L.; Deng, Z.Y. Efficacy of the ladybird beetle Cryptolaemus montrouzieri Mulsant for control of Saccharicoccus sacchari (Cockerell). Sugar Tech. 2017, 19, 599-603. [CrossRef]

28. Qin, Z.Q.; Qiu, B.L.; Wu, J.H.; Cuthbertson, A.G.S.; Ren, S.X. Effects of three mealybug species on the development, survivorship and reproduction of the predatory lady beetle Cryptolaemus montrouzieri Mulsant. Biocontrol Sci. Techn. 2014, 24, 891-900. [CrossRef]

29. Silva, P.G.D.; Hagen, K.S.; Gutierrez, A.P. Functional response of Curinus coeruleus (Col.: Coccinellidae) to Heteropsylla cubana (Hom.: Psyllidae) on artificial and natural substrates. Entomophaga 1992, 37, 555-564. [CrossRef]

30. Papanikolaou, N.E.; Martinou, A.F.; Kontodimas, D.C.; Matsinos, Y.G.; Milonas, P.G. Functional response of immature stages of Propylea quatuordecimpunctata (Coleoptera: Conccinellidae) to Aphis fabae (Hemiptera: Aphididae). European J. Entomol. 2011, 108, 391-395. [CrossRef]

31. Madadi, H.; Parizi, E.M.; Allahyari, H.; Enkegaard, A. Assessment of the biological control capability of Hippodamia variegata (Col.: Coccinellidae) using functional response experiments. J. Pest Sci. 2011, 84, 447-455. [CrossRef]

32. Houck, M.A.; Strauss, R.E. The comparative study of functional response: Experimental design and statistical interpretation. Can. Entomol. 1985, 117, 617-629. [CrossRef]

33. Martinou, A.F.; Raymond, B.; Milonas, P.G.; Wright, D.J. Impact of intraguild predation on parasitoid foraging behaviour. Ecol. Entomol. 2010, 35, 183-189. [CrossRef]

34. Hodek, I. Food Relationships. In Ecology of Coccinellidae; Hodek, I., Honĕk, A., Eds.; Kluwer Academic Publishers: Dordrecht, The Netherlands, 1996; pp. 143-238. 
35. Jayanthi, P.D.K.; Rajinikanth, R.; Ravishankar, K.V.; Sangeetha, P.; Verghese, A.; Lokeshwari, D. Influence of cGMP on feeding potential of predatory Coccinellid, Cryptolaemus montrouzieri Mulsant and isolation of partial foraging Gene. J. Insect Behav. 2014, 27, 385-394. [CrossRef]

36. Mani, M.; Krishnamoorthy, A. Australian ladybird beetle, Cryptolaemus montrouzieri. Madras Agric. J. 1997, 84, $237-249$.

(C) 2019 by the authors. Licensee MDPI, Basel, Switzerland. This article is an open access article distributed under the terms and conditions of the Creative Commons Attribution (CC BY) license (http://creativecommons.org/licenses/by/4.0/). 